\section{Outrage at high price paid for a fossil}

SIR - In your Editorial 'Media frenzy' (Nature 459, 484; 2009), you discuss the hype surrounding the description of a 47-millionyear-old fossil primate (J. L. Franzen et al. PLoS ONE 4, e5723; 2009). This fossil was publicized worldwide by the press using banners such as "the eighth wonder of the world" and "the missing link in human evolution", although no such claims were made by the authors in the paper. But even more outrageous, in our view, was the earlier sale of this specimen for a huge sum.

The fossil, nicknamed 'Ida', was allegedly found by an amateur collector (C. Tudge The Link 68-69, Little, Brown, 2009) in 1983 at the Grube Messel site in Germany.

Ida's collector separated this fossil into two parts, which was unfortunate because of the scientific value of completeness. The less-complete part, now known as the B side, reportedly had some of its anatomical features fabricated to make it seem more complete (see J. L. Franzen et al. PLOS ONE 4, e5723; 2009), perhaps to facilitate its independent sale.

The B side was sold to Burkhard Pohl of the Wyoming Dinosaur Center in Thermopolis, then sent to Jens Franzen of the Senckenberg Research Institute in Frankfurt, Germany, who described it in 1994. Meanwhile, the more complete part of Ida, now known as side $A$, was embedded in resin and framed. It is believed to have been kept in the anonymous collector's home for 23 years until 2006, when its photograph was shown to Jørn Hurum of the Natural History Museum in Oslo.

The asking price for side $\mathrm{A}$ was reportedly US $\$ 1$ million, although Hurum is alleged to have eventually paid about $\$ 750,000$ for it (see The Times Online, 28 May 2009). The publicity barrage surrounding this fossil seems

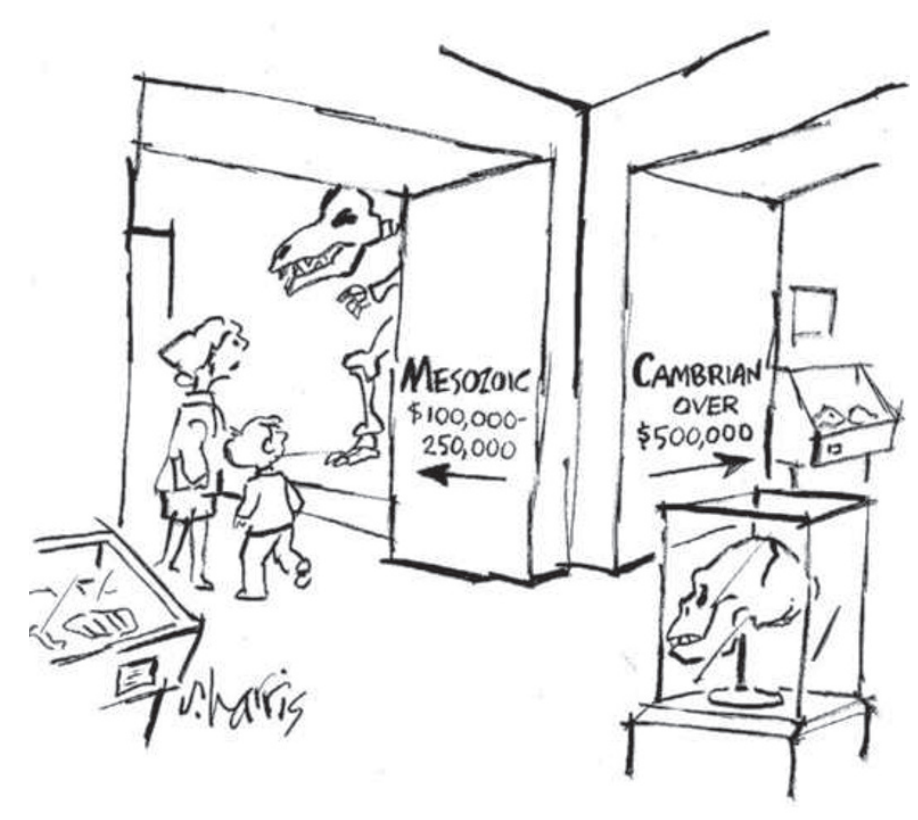

to have been amplified by its purchase for this sum of money.

In our view, such objectionable pricing and publicity can only increase the difficulty of scientific collecting by encouraging the commercial exploitation of sites and the disappearance of fossils into private collections. We believe that payments on this scale are detrimental to scientific investigation, and respectable institutions should not be responsible for making or publicizing them. We strongly believe that fossils should not have any commercial value.

Elwyn L. Simons, Friderun AnkelSimons, Prithijit S. Chatrath Duke Lemur Center, Durham, North Carolina e-mail: esimons@duke.edu

Richard S. Kay, Blythe Williams

Evolutionary Anthropology Department, Duke University John G. Fleagle Department of Anatomy, State University of New York, Long Island

Daniel L. Gebo Department of Anthropology, Northern Illinois University

Christopher K. Beard, Mary Dawson Carnegie Museum, Pittsburg Ian Tattersall Department of Anthropology, American Museum of Natural History

Kenneth D. Rose Center for Functional Anatomy and Evolution, Johns Hopkins University School of Medicine

\section{Peer review and impact statements vital to UK research}

\section{SIR - Cameron Neylon's}

Correspondence 'Funding ban could break careers at the toss of a coin' (Nature 459, 641; 2009) is an example of some of the negative reactions to the proposed changes in the peerreview system used for grant applications at the UK Engineering and Physical Sciences Research Council (EPSRC). However, the process will continue to be fair, open and transparent, being undertaken by the research community itself to ensure that only work of the highest quality is funded by the EPSRC.

I have been reported as saying that peer review is "a lottery", but this was intended as a description for what can happen when success rates are too low. That is one reason why we have recently introduced measures to reduce the number of poor-quality proposals and so alleviate pressure on our peerreview process. Success rates will improve with fewer, more considered proposals.

The global financial crisis has boosted interest in science and engineering's contribution to future prosperity and in tackling global challenges. It has also never been more important to justify how we spend public money. This is why the research councils are working together to highlight the impact of the research we fund.

Some people have reacted strongly to the requirement for proposals to include an outline of the "potential economic impact" of the research. This has been taken to mean purely financial or commercial impact, whereas the definition consistently used by the research councils is much broader and embraces all the diverse ways in which research-related knowledge and skills could benefit individuals, organizations and nations. For example, high-quality research can lead to improved environmental measures, better communications, new products and services and better-informed public policy.

The primary criteria used to judge proposals remain international excellence and quality. We simply want to ensure that our researchers have considered the impact of their work from the outset.

There have been concerns that the emphasis on impact will draw attention away from blue-skies research. But the EPSRC is fully committed to investigator-led research and understands that this is where future generations of technology will come from.

Our mission remains unchanged - to promote and support, by any means, highquality basic, strategic and applied research, thereby contributing to the economic competitiveness of the United Kingdom and our quality of life.

We must all work together to demonstrate the impact that science and engineering have on society, to ensure continued public support and government funding for research.

David Delpy Engineering and Physical Sciences Research Council, Polaris House, North Star Avenue, Swindon SN2 1ET, UK e-mail david.delpy@epsrc.ac.uk 